\title{
Aplicação do Método de Preços Hedônicos na Precificação de Atributos Raros de Peças Filatélicas e Construção de Carteiras Eficientes
}

\author{
- Sandro de Freitas Ferreira*
}

\author{
- Moisés de Andrade Resende Filho**
}

\begin{abstract}
Resumo
Este trabalho aplica modelos de preços hedônicos na estimação do valor das características implícitas de selos postais imperiais brasileiros emitidos de 1843 a 1889, com base em suas cotações anuais no período 1954 a 1988. Os preços implícitos estimados são utilizados para gerar os retornos médios e matriz de variâncias-covariâncias, necessários à aplicação do método de Markowitz na construção das carteiras eficientes. As evidências encontradas mostram que carteiras eficientes seriam formadas por um reduzido número de selos. Além disso, os resultados indicam que a compra de selos não seria lucrativa.
\end{abstract}

\section{Palavras-Chave}

avaliação de ativos tangíveis, método de preços hedônicos, investimentos, carteiras eficientes, colecionismo, selos postais

\begin{abstract}
This work applies hedonic pricing method to estimate the implicit value of rare attributes of stamps issued during the Brazilian imperial period (1843-1889), using their annual prices between years 1954 and 1988. First, estimated implicit prices are used in calculating average returns and their variance-covariance matrix. Second, these results are employed in the construction of efficient portfolios using Markowitz' approach. Results show evidences that efficient portfolios should be composed of few stamps. Moreover, we found that investing in stamps is not profitable.
\end{abstract}

\section{Keywords}

tangible asset valuation, hedonic price models, investments, efficient portfolio, collectibles, postage stamps

\section{JEL Classification}

D14, G11, G12

\footnotetext{
* Departamento de Análise Econômica, Universidade Federal de Juiz de Fora (UFJF). E-mail: sandroffbr@ yahoo.com.br.

** Departamento de Análise Econômica, Universidade Federal de Juiz de Fora (UFJF). E-mail: moises. resende@ufjf.edu.br.

Endereço para contato: Campus Universitário - Universidade Federal de Juiz de Fora - Juiz de Fora - MG. CEP: 36036-330.

(Recebido em maio de 2008. Aceito para publicação em abril de 2009).
} 


\section{Introdução}

O ato de colecionar pode ser visto como um paradigma do ato de consumir. Bianchi (1997) advoga que o ato de colecionar é uma etapa anterior ao ato de consumir, porque a construção do conjunto consumo deriva dos mesmos procedimentos da construção do que ela chamou "conjunto coleção". Entretanto, é também um ato de investir.

Objetos de coleção são cogitados na composição de carteiras de investimentos. Damodaran (1999, p. 593) afirma que, apesar de esses tipos de ativos se caracterizarem por não gerar fluxos de caixa periódicos, "alcançam valor porque são escassos e/ou são percebidos como valiosos e/ou geram utilidade para aqueles que os possuem". Além disso, são semelhantes a um título de cupom zero, em que a realização de ganhos somente se dá com a diferença entre o valor de revenda e o preço de compra da peça (FABOZZI, 2002).

Esses ativos incomuns têm características sui generis: há casos em que tais objetos são únicos; em muitos de seus mercados, os colecionadores são mais comuns do que os especuladores; têm baixo grau de liquidez; não são transacionados com frequência; o preço fechado na transação normalmente não é de conhecimento público, mas só das partes envolvidas, e nem sempre há preços de referência que auxiliem no processo de avaliação de peças da mesma categoria.

Burton e Jacobsen (1999) conduziram uma meta-análise de estudos referentes a retornos sobre investimentos em objetos colecionáveis, tais como móveis antigos, moedas, desenhos e pinturas, fotografias, impressos, selos, vinhos, etc., para vários períodos entre 1925 a 1999. Eles mostraram que: quase nenhum estudo evidenciou uma taxa nominal de retorno negativa; embora existam algumas taxas reais de retorno negativas, não são grandes em termos absolutos; a maioria dos objetos estudados gerou retornos menores do que os retornos das ações no mesmo período; aqueles estudos que incorporaram alguma medida de variabilidade ao longo do tempo encontraram evidências de que os retornos são mais voláteis do que os dos demais ativos financeiros, e os objetos de coleção frequentemente oferecem taxas de retorno inferiores àquelas dos títulos públicos. ${ }^{1}$

Há quem afirme que os objetos de coleção são passíveis de participar em estratégias de hedge. Ibbotson e Brinson (1987) mostram que eles podem prover hedge contra a inflação. Kane (1984) encontrou evidências de que algumas moedas antigas norteamericanas poderiam ter sido utilizadas contra a inflação durante os anos de 1970

1 Segundo os mesmos pesquisadores, esse comportamento poderia sugerir efeitos não pecuniários elevados para alguns objetos colecionáveis. 
até o começo dos anos de 1980. Cardell et al. (1995), num estudo sobre o potencial de selos postais norte-americanos em hedging, afirmam que podem ser utilizados contra alguns fatores de risco, tais como inflação, default e estrutura a termo da taxa de juros, mas que não são hedges perfeitos contra esses fatores. Advertem também que os selos podem ser úteis, em conjunto com outros ativos, na estruturação de portfólios, na medida em que dão exposições alternativas aos riscos sistêmicos. Contudo, não existe consenso sobre os benefícios pecuniários dessa estratégia nas decisões de carteira. Ademais, poucos estudos têm focalizado atenção neste tema.

Selos postais são sugeridos para compor carteiras de investimento, por apresentarem mercados geográfica e historicamente conhecidos: nas principais cidades do mundo, desde o século 19, já havia negociantes e compradores. O senso comum e a experiência dos participantes desses mercados sugerem que eles são uma boa alternativa de investimento, devido à valorização das peças ao longo dos anos (oferta fixa e demanda crescente). Entretanto, são ativos com reduzido grau de liquidez e comercializados em mercado de balcão.

Independentemente disso, selos postais são objetos heterogêneos: possuem atributos (ou características) que diferenciam as emissões entre si e, em alguns casos, diferenciam selos de uma mesma emissão, como nos casos em que há variações de cor, papel, erros de impressão ou outras (conhecidas como variedades). Esses atributos são informações conhecidas pelos negociantes e compradores.

Atributos diferenciados conduzem a preços de mercado diferenciados. Os catálogos especializados e as listas de leilóes e de ofertas de compra e venda de selos postais apresentam cotações diferenciadas para objetos aparentemente iguais, refletindo diferenças nas características. Portanto, pode-se supor que esses atributos possuem valor de mercado, apesar de não serem isoladamente comercializados.

Agentes econômicos procuram atributos raros para compor distintamente suas coleções ou, até mesmo, suas carteiras de investimento em peças filatélicas, para auferir ganhos não pecuniários ou ganhos advindos da apreciação ao longo do tempo ou mesmo como reserva de valor. Se o valor desses atributos de raridade determina os preços dos selos postais, então dever-se-ia focar atenção nas trajetórias e características dos retornos desses ativos-atributos em decisões de portfólio.

Partindo-se desta hipótese, antes do processo de composição de uma carteira de ativos, convém avaliar os atributos dos objetos de coleção ao longo do tempo; cujos preços implícitos darão origem à análise de portfólio. Assim, procura-se averiguar quais selos postais deveriam compor a carteira de ativos de um colecionador-investidor a partir do comportamento dos retornos de suas características filatélicas. 
Para tanto, avaliam-se os atributos dos selos postais imperiais brasileiros (emitidos de 1843 a 1889), mediante a utilização da abordagem dos preços hedônicos de Rosen (1974), empregando-se as cotações anuais referentes ao período 1954-1988. Em seguida, utilizam-se as estimativas dos preços hedônicos na construção das séries temporais de "retornos implícitos"² históricos dos atributos filatélicos e, a partir destas, carteiras eficientes de ativos implícitos ${ }^{3}$ são construídas.

No presente artigo, primeiramente faz-se uma revisão sucinta da literatura sobre mercados filatélicos. Em seguida, na seção 2, procede-se a uma breve descrição da abordagem dos preços hedônicos. A seção 3 descreve os métodos de análise empregados. Na seção 4, são apresentados e analisados os resultados alcançados. Finalmente, são discutidas as limitações e as possíveis extensões deste estudo na seção de conclusão.

\section{A Literatura sobre Selos e Mercados Filatélicos}

A literatura econômica referente aos selos e aos mercados filatélicos é escassa. Os principais temas de pesquisa estão focados na demanda filatélica, análise de retorno de investimento em selos e estratégia de hedge, análise do comportamento dos participantes nesses mercados e comportamento dos leilóes e eficiência das casas de leilões. Apesar disso, as pesquisas não são sistemáticas.

Pode-se dizer que Schnitzel (1979) foi o pioneiro na introdução da análise econômica nas atividades associadas aos selos. Ele tratou diretamente da demanda filatélica e sugeriu um modelo para selos novos ${ }^{4}$ e usados, ${ }^{5}$ pressupondo uma demanda dependente da escassez percebida, que, por sua vez, é função da quantidade emitida e da idade da emissão.

A partir da constatação de que os mercados filatélicos são caracterizados por variação de qualidade dos ativos transacionados, Taylor (1983) analisou o comportamento dos retornos, levando em consideração taxas ajustadas pela qualidade, e sugeriu índices de preços.

2 A título de distinção dos retornos comumente conhecidos, denominou-se "retorno implícito" aquele que é calculado a partir dos preços implícitos.

3 Semelhantemente ao caso do termo "retorno implícito", denominou-se "ativo implícito" a característica geradora de valor.

4 Peça filatélica que não foi utilizada para pagamento do transporte da correspondência; possivelmente ainda possui a goma no reverso.

5 Peça filatélica que foi carimbada; inutilizado com a marca de um carimbo para confirmar o pagamento pelo serviço de transporte. 
Conforme abordado anteriormente, Cardell et al. (1995) verificaram a potencialidade dos selos americanos como ativos passíveis de serem empregados em estratégias de hedge contra a inflação e/ou contra outras fontes de risco sistêmico.

Huang (2001) estudou o comportamento dos participantes do mercado filatélico chinês que, segundo ele, conhecido como "The Second Stock Market in China", tem crescido rapidamente nas duas últimas décadas e se tornado lucrativo. Nele, os preços dos selos recentemente emitidos apreciam em maior velocidade do que os selos emitidos há muitas décadas passadas. Esse comportamento dos preços contraria as evidências nos mercados filatélicos ocidentais. Huang explica que este efeito é causado pela assimetria de participação dos colecionadores e dos investidores no mercado.

Há também alguns interessantes estudos sobre o mercado filatélico, em particular aqueles em que os leilões são utilizados. Taylor $(1983,1995)$ analisa o comportamento das séries temporais dos preços formados em leilões de selos. Lucking-Reiley (2000a) descreve sucintamente o desenvolvimento dos leilóes on-line e o que está sendo leiloado e como está sendo leiloado. O mesmo pesquisador (Lucking-Reiley, 2000b) trata especificamente dos leilões de Vickrey num caso particular - leilões filatélicos. Villani Jr. (2001) propõe um modelo para descrever um leilão ascendente (leilões on-line) e verifica seu comportamento. Por outro lado, Sáez e Achaerandio (2004) tratam da eficiência técnica das casas de leilões de selos. Eles verificaram se elas se aproximam ou não da eficiência técnica e concluem que não; ao contrário, são ineficientes.

\section{Preços Hedônicos}

A abordagem dos preços hedônicos (ou preços implícitos), como método de avaliação de bens, tem por base a hipótese de Lancaster (1966) de que os atributos de uma determinada mercadoria têm valor por propiciar utilidade a quem os consome. Desse modo, os atributos são responsáveis por parte do valor de mercado de um bem e é possível afirmar que há uma relação entre seu valor e suas características. Contudo, elas não são avaliadas isoladamente.

A partir disso, Lancaster configurou dois estágios de relações entre indivíduos, bens e características: uma relação entre bens e suas características (relação técnica), e uma relação entre indivíduos e características (relações de preferências individuais). Desse modo, com base nessas relações, é possível construir vários modelos funcionais. 
Rosen (1974), por outro lado, propõe um caso particular desses modelos em que a relação de dependência é estabelecida entre o preço do bem e suas características, conduzindo à função preço hedônico. Este procedimento é conhecido como abordagem dos preços hedônicos.

A perspectiva hedônica provê um método que identifica a estrutura dos preços dos atributos que compõem a mercadoria heterogênea, mediante a estimação da função que relaciona o preço dessa mercadoria com os preços dos diferentes atributos desse produto (preços implícitos).

Os preços dos atributos são revelados, para os agentes econômicos, a partir dos preços efetivamente observados dos produtos heterogêneos e dos montantes dos atributos componentes. A título de formalização, seguindo Rosen (1974), seja o preço do $j$-ésimo bem, composto de $k$ características, dado por $p_{j}(c)=p_{j}\left(c_{1 j}, c_{2 j}, \ldots, c_{k j}, \ldots, c_{K j}\right)$, onde $c_{k j}$ é a $k$-ésima característica do bem $j$ e $p_{j}($. é a função preço hedônico (FPH).

Uma vez estimada a FPH, o preço implícito da $k$-ésima característica, $p_{k}$, é diretamente obtido derivando-se a FPH com respeito a $k$-ésima característica, ou seja, $p_{k}=\frac{\partial p_{j}(\bullet)}{\partial c_{k}}$. Este resultado fundamenta-se no modelo de Rosen (1974), segundo o qual a FPH resulta do equilíbrio entre a oferta e a demanda por atributos que, por sua vez, são derivadas dos equilíbrios econômicos dos produtores e dos consumidores de atributos. Ressalte-se que a implementação da estimação admite implicitamente que há disponível no mercado uma variedade de produtos heterogêneos, de tal maneira que os agentes econômicos possam escolhê-los, considerando seus níveis de satisfação e suas restrições orçamentárias (definidas por suas rendas e pelos preços das mercadorias compostas).

Segundo Bajari e Benkard (2005), a abordagem de Rosen solidificou a teoria hedônica e permitiu sua aplicação em ampla variedade de áreas, que vão desde habitação, economia do setor público, economia ambiental, mercado de trabalho, até marketing e organização industrial.

Além de sua proposta teórica, Rosen (1974) desenvolveu também um método empírico para estimar os parâmetros das funções demanda e oferta de atributos. Entretanto, a aplicação de sua estratégia de estimação, conforme mostram Brown e Rosen (1982), Epple (1987), Bartik (1987) e Kahn e Lang (1988), conduz a procedimentos inadequados de estimação que dão origem a estimativas inconsistentes dos parâmetros das funções de demanda e oferta. 
Epple (1987, p. 60) afirma que a chave para a solução dos problemas de identificação e de estimação nos modelos hedônicos está em uma "declaração precisa das condições de ortogonalidade entre as variáveis medidas e os componentes aleatórios de tais modelos". Na mesma linha de raciocínio de Epple, Bartik (1987) também afirma que os procedimentos padrões para estimar os parâmetros de demanda em modelos de preço hedônico levam a resultados viesados e propõe como solução a utilização de variáveis instrumentais.

Independentemente destas questões, as FPHs são estimadas, segundo Sheppard (1999), com dois propósitos essenciais: (a) para a construção de índices de preços, que levam em consideração as mudanças de qualidade dos atributos componentes dos pacotes transacionados e (b) para a análise da demanda por atributos de mercadorias heterogêneas.

O presente artigo propõe uma terceira aplicação: a construção de carteiras de investimentos em ativos implícitos a partir dos retornos calculados com os preços implícitos estimados dos atributos de uma mercadoria heterogênea.

Esta proposta está fundamentada na seguinte proposição: dado que os ativos tangíveis possuem atributos que lhes adicionam valor (ativos implícitos) e que lhes subtraem valor (passivos implícitos) e dado que os investidores mantêm tais ativos em carteira, mas que não estão interessados nos ativos em si, é possível que estejam interessados no comportamento do valor de seus atributos (que apreciam, preservam ou mesmo depreciam ao longo do tempo). Assim sendo, justifica-se a avaliação desses atributos, mediante a FPH, e o acompanhamento das trajetórias temporais de seus retornos implícitos.

A partir dos preços implícitos estimados, calcula-se os retornos implícitos desses ativos-atributos e suas variâncias e covariâncias que são os inputs à obtenção das carteiras eficientes de atributos à la Markowitz (1952).

A justificativa para a utilização do método dos preços hedônicos (MPH) nos estudos econômicos dos selos postais, em particular dos selos postais imperiais brasileiros, tem o respaldo de outros estudos de avaliação de objetos raros. Buelens e Ginsburgh (1993) aplicaram o MPH para avaliar preços de obras de arte, Dickie et al. (1994) também utilizam-se desta abordagem, mas num estudo de moedas raras. Schnitzel (1979) propôs um modelo hedônico para precificar selos, em que a diferença entre o preço corrente e o valor de face do selo é função da tiragem (quantidade emitida) e da idade (diferença entre a data de emissão e a data corrente). Huang (2001) também utiliza o MPH, mas diferentemente de Schnitzel (1979) introduz outras variáveis explicativas (valor de face, ano de emissão, número de selos por emissão, 
etc.). Contudo, tais estudos não vislumbraram a possibilidade da alternativa de aplicação dos preços hedônicos na construção de carteiras de atributos.

\section{Método Empregado}

\subsection{Definição das Variáveis do Modelo}

Uma vez que não há uma teoria a respeito dos determinantes da cotação de uma peça filatélica, a escolha das variáveis explicativas seguiu Schnitzel (1979) e Huang (2001), mas foram adicionadas outras variáveis (dummies e não dummies), além de idade da emissão. Note-se que Schnitzel utiliza idade da emissão e tiragem. Não há informações sobre as tiragens dos selos com variedades; portanto, ela foi excluída da FPH.

Levam-se em consideração como determinantes dos preços dos selos postais imperiais brasileiros: (i) um conjunto de características intrínsecas ao selo: gramatura do papel (fina, média, grossa), cor do papel (branca, acinzentada ou amarelada, acinzentada ou azulada, amarelada ou azulado), textura do papel (lisa ou estriado), presença de denteação, tipo de denteação (denteados ou percé) ${ }^{6}$ número de denteados (para os selos com denteados), cor da impressão, tipo de imagem estampada (algarismos, efígie do Imperador, outras), valor de face; (ii) um conjunto de características extrínsecas ao selo: idade, presença de carimbo, selo isolado, ${ }^{7}$ par de se$\operatorname{los}^{8}$, terno de selos, ${ }^{9}$ quadra de selos, ${ }^{10}$ cinco selos, seis selos, selo fixado em algum suporte, ${ }^{11}$ selo bisseto, ${ }^{12}$ (iii) um conjunto de variedades: variedade na gramatura de papel, variedade na cor do papel, variedade na textura do papel, variedade da cor de impressão, variedade no tipo de denteação, variedade no tipo de papel (papel tintado ou não tintado), presença de erro de impressão e presença de legenda nas

6 Tipo de denteação em que os selos são separados por denteação em linha.

7 Selo não fixado em um envelope, pedaço de papel, jornal ou algo semelhante.

8 Dois selos justapostos na margem vertical (esquerda ou direita) ou na margem horizontal (inferior ou superior); também conhecidos como pares.

9 Três selos justapostos (formando seis combinações possíveis); também conhecidos como ternos.

10 Quatro selos justapostos (as margens unidas formam o desenho de uma cruz); conhecidos como quadras.

11 Suporte é qualquer material derivado do papel utilizado para guardar e proteger a correspondência, tal como envelope, fragmento de envelope, sobrecarta, cartão postal, cinta de jornal etc.

12 Selo bisseto é uma denominação utilizada para classificar os selos que foram cortados ao meio (vertical ou diagonalmente) como forma de equiparação do valor de face ao valor do porte da correspondência, quando da ausência de selos com o devido valor de face. Por exemplo, o selo de D. Pedro II Percé de 200 réis foi transformado em bisseto para pagamento de porte de 100 réis. 
margens dos selos. O Quadro 1 lista todas as características adotadas nos modelos de regressão, com suas respectivas siglas. ${ }^{13}$

\begin{tabular}{|c|c|c|c|}
\hline Características Gerais & $\begin{array}{l}\text { Características } \\
\text { Secundárias }\end{array}$ & Especificidades & $\begin{array}{l}\text { Legenda da } \\
\text { Variável }\end{array}$ \\
\hline \multirow[t]{3}{*}{ Papel } & Gramatura & $\begin{array}{l}\text { fina } \\
\text { média } \\
\text { grossa }\end{array}$ & $\begin{array}{l}\text { DPPF } \\
\text { DPPM } \\
\text { DPPG }\end{array}$ \\
\hline & Textura & vergé (estriada) & DTXVG \\
\hline & Cor & $\begin{array}{l}\text { branca } \\
\text { acinzentada/amarelada } \\
\text { acinzentada/azulada } \\
\text { amarelada/azulada }\end{array}$ & $\begin{array}{l}\text { DPPBR } \\
\text { DPPACAM } \\
\text { DPPACAZ } \\
\text { DPPAMAZ }\end{array}$ \\
\hline \multirow[t]{3}{*}{ Denteação } & Presença de denteação & & DPRDT \\
\hline & Tipo de Denteação & $\begin{array}{l}\text { Denteados } \\
\text { Percé (em linha) }\end{array}$ & $\begin{array}{l}\text { DDT } \\
\text { DPERC }\end{array}$ \\
\hline & Número de Denteados & & NDT \\
\hline Imagem & Tipo de Imagem & $\begin{array}{l}\text { Algarismos } \\
\text { Efígie de DPII } \\
\text { Outras } \\
\end{array}$ & $\begin{array}{l}\text { DIMALG } \\
\text { DIMEFI } \\
\text { DIMOUT }\end{array}$ \\
\hline Cor da Impressão & Presença de cor & & DPRCOR \\
\hline Valor de Face (Real) & & & VF \\
\hline Idade & & & ID \\
\hline Selo Novo & & & DSN \\
\hline Número de Selos na Peça Filatélica & & & NSP \\
\hline Selo Isolado & & & D1S \\
\hline Par de Selo & & & D2S \\
\hline Terno de Selos & & & D3S \\
\hline Quadra de Selos & & & D4S \\
\hline Cinco Selos & & & D5S \\
\hline Seis Selos & & & D6S \\
\hline Selos Fixados em Suporte & & & DENV \\
\hline Selo Bisseto & & & DBSS \\
\hline Presença de pelo Menos uma Variedade & & & DPRAR \\
\hline \multirow[t]{4}{*}{ Presença de Variedade } & $\begin{array}{l}\text { no papel } \\
\text { no tipo de papel }\end{array}$ & $\begin{array}{l}\text { Gramatura } \\
\text { Textura } \\
\text { Cor } \\
\text { Papel Tintado } \\
\end{array}$ & $\begin{array}{l}\text { DVRGR } \\
\text { DVRTX } \\
\text { DVRCPP } \\
\text { DPPTIN }\end{array}$ \\
\hline & na cor & & DVRCOR \\
\hline & na impressão & $\begin{array}{l}\text { erro de impressão } \\
\text { legenda na margem do selo }\end{array}$ & $\begin{array}{l}\text { DVRIMP } \\
\text { DLGMRG }\end{array}$ \\
\hline & na denteação & & DVRDT \\
\hline Número de Variedades no selo & & & NVR \\
\hline
\end{tabular}

Fonte: Elaboração própria dos autores a partir de informações coletadas dos catálogos de selos.

\section{Quadro 1 - Vetor de Características Intrínsecas, Extrínsecas e de Variedades do Selo Postal Imperial Brasileiro}

13 Todas as variáveis do tipo dummy são denotadas pela letra D. As demais são do tipo contínuo. 
A variável dependente é representada pelo "Valor Real da Cotação (VR)", atualizado para reais de 2007. Como se deseja captar o valor marginal de cada uma das características e das variedades, deve-se construir uma base de dados que reflita esta proposta. Para tanto, foram coletados os preços (cotações) e as características de cada peça filatélica e para cada ano.

Para cada emissão, coletaram-se informações de suas características (a partir dos catálogos de selos, que são invariantes ${ }^{14}$ ao longo do tempo, exceto a referente à idade da emissão) e das cotações das peças novas e usadas, com e sem variedades, dos selos isolados, pares de selos, ternos de selos, quadra de selos, cinco selos, seis selos e dos selos fixados sobre algum suporte (neste caso não há peças novas; todas estão carimbadas) e dos selos bissetos.

As cotações são anuais e foram coletadas a partir das seguintes publicações anuais: Catálogo de Selos do Brasil ${ }^{15}$ (1954 a 1963, 1965, 1970 a 1974), Catálogo de Selos do Brasil ${ }^{16}$ (1964 e 1966 a 1968) e Catálogo de Selos Brasil da Rolf Harald Meyer (1975 até 1988). Essas cotações, conforme informação extraída dos próprios catálogos, dizem respeito aos resultados de leilões e de ofertas de compra e venda dos comerciantes filatélicos. Esse processo de precificação está nitidamente declarado nos catálogos da firma Rolf Harald Meyer, que possivelmente seguiu os procedimentos de coleta da firma Francisco Schiffer. Entretanto, não está disponível qualquer informação desse tipo nos catálogos da firma Santos Leitão. Por isso, não é possível afirmar que todas as cotações sejam referentes a preços de equilíbrio.

As cotações foram ajustadas ao valor do período-base 2007, com base no índice de preços IGP-DI da FGV e procedendo-se à devida conversão da moeda da época para reais.

Neste estudo, foram utilizadas 24.278 cotações anuais distribuídas por 35 anos (1954 e 1988), porém a quantidade de cotações, para cada ano, não permaneceu constante ao longo dos anos. Os catálogos de 1954 a 1978 apresentaram uma média de 581 cotações. Entre 1979 e 1984, o número de cotações saltou para o patamar médio de 826 cotações e, a partir de 1985, para um pouco mais de 1200 cotações.

14 Ao longo dos anos, algumas mudanças na catalogação dos selos foram feitas. Este trabalho leva em consideração tais modificações. Por exemplo, o selo Cabecinha (emitido em 1884) era incluído na última série emitida antes do fim da monarquia. Atualmente, ele é considerado uma emissão isolada.

15 Publicado pela Casa Filatélica Francisco Schiffer de 1943 até 1974. A partir de 1975, os catálogos passaram a ser publicados pela firma Rolf Harald Meyer com o nome Catálogo de Selos Brasil.

16 Publicado pela Casa Filatélica Santos Leitão e Cia Ltda. de 1937 até, pelo menos, 1967. 
As mudanças de nível da quantidade de cotações anuais refletem a introdução de novas cotações. ${ }^{17}$

\subsection{Perfil das Peças Filatélicas Imperiais Brasileiras}

O estudo dos selos imperiais brasileiros requer a compatibilização das catalogações dos selos ao longo do tempo, pois os editores dos catálogos não mantiveram as mesmas numerações ao longo do tempo. ${ }^{18}$

Em relação às características intrínsecas ao selo, em média, 53\% das cotações se referem a selos que foram impressos em papel fino, 45\% em papel médio e somente 1,8\% em papel grosso (a proporção de selos em papel de gramatura média só supera a de gramatura fina a partir do ano de 1979). Em termos de cor do papel, em média, a maioria das cotações diz respeito a selos impressos em papel branco (cerca de $61 \%$ ), as demais, em papel amarelado/azulado, papel acinzentado/amarelado e papel acinzentado/azulado, 19,3\%, 9\% e 8,9\%, respectivamente; que se mantiveram nesses níveis ao longo dos anos. E, no que se refere à textura do papel (cujos selos do período imperial, foram emitidos somente em papel liso ou papel estriado), ao longo dos anos, a proporção de cotações referentes a selos em papel estriado diminuiu (caiu de 30\% para 20\%). Em contrapartida, a de papel liso aumentou.

Em média, 68,7\% das cotações se referem a selos com algum tipo de denteação e $31,3 \%$, àqueles sem denteação (selos que eram destacados mediante tesoura). Dos selos com algum tipo de denteação, em média, 21,1\% tiveram denteação percé e 47,3\% com denteados. Essas participações permaneceram estáveis ao longo do tempo.

Em relação às participações das características cor e imagem no montante de cotações, em média, 30,5\% das cotações coletadas são de selos impressos em cor preta e os restantes 69,5\%, em outra cor. E 34,3\% com imagens de algarismos arábicos, $55,7 \%$ com a efígie do imperador Dom Pedro II e somente 10,1\% com outro tipo de imagem. ${ }^{19}$

17 Até 1978, só havia cotações para selos isolados novos, isolados usados, pares novos, pares usados, quadras novas, quadras usadas e para os selos com e sem variedades. Em 1979, foram adicionadas muitas cotações referentes às variedades existentes nas emissões de 1866, 1876 e 1877-78. E, a partir de 1985, foram introduzidas cotações de ternos novos, ternos usados e selos (isolados, pares, ternos, quadras, tiras, cinco ou seis selos) fixados em algum tipo de suporte.

18 A título de exemplificação, os catálogos dos anos de 1954 a 1977 apresentaram algumas variedades que não foram consideradas para os anos seguintes. Possivelmente, à época, um consenso a respeito de como elas deveriam ser classificadas ainda não havia sido alcançado. Neste estudo, elas foram consideradas como eram vista naquela época. As devidas precauções foram tomadas.

19 A partir de 1980, os catálogos daquele e dos demais anos passaram a apresentar cotações adicionais dos selos contendo a efígie de D. Pedro II com legenda da firma tipográfica na margem 
No que diz respeito às características extrínsecas ao selo, cerca de 48,3\% das cotações são de selos novos e 51,7\%, de selos usados (ou carimbados). Além disso, $45,7 \%$ são de selos isolados, $26,7 \%$ de pares de selos, 25,2\% de quadras de selos; os demais, que são a minoria, de ternos de selos e conjuntos de cinco e seis selos. As observações referentes aos selos fixados em algum tipo de suporte e aos selos bissetos, em média, foram somente 3\% e 1,3\%, respectivamente. E o número médio de selos numa peça filatélica é de duas unidades.

A proporção de cotações referentes a selos com pelo menos uma variedade mantevese no patamar dos 30\% entre 1954 e 1979. A partir daquele ano, saltou para cerca de $45 \%$. Em relação às variedades ligadas às características intrínsecas aos selos, em média, 3\% contêm variedade na gramatura do papel, 8,2\%, na cor do papel, $0,4 \%$, na textura do papel, 4,9\%, no tipo de denteação empregado para destacar os selos e 12,5\%, na cor da impressão. Em média, apenas 7,7\% das observações apresentam algum erro de impressão, $1,7 \%$ foi impressa em papel tintado e somente $2,5 \%$ apresentam a legenda da firma tipográfica em uma das margens do selo.

Em suma, poder-se-ia afirmar que, se se tomasse as maiores proporções médias como definidores das características de um selo postal imperial brasileiro, ele seria representado por um selo isolado, com marca de carimbo, com impressão em cor, da efígie de D. Pedro II, sobre papel branco fino em textura lisa, com denteados e sem variedade. Neste caso, seria representado por qualquer emissão das séries de D. Pedro II de 1876 a 1878.

\subsection{Especificação Funcional}

Em relação à forma da $\mathrm{FPH}$, a literatura da abordagem hedônica não prescreve uma forma funcional específica. Neste estudo, seguindo estudos semelhantes (SCHNITZEL, 1979, BUELENS; GINSBURGH, 1992, DICKIE et al., 1994; HUANG, 2001), empregaram-se as formas paramétricas tradicionais: linear, semilogarítmica (log-linear) e dupla-logarítmica $(\log -\log )$ para a relação preço-atributos.

Dado que não se está interessado na demanda nem na oferta dos atributos e que a FPH é uma relação "na forma reduzida" combinando informações da oferta e demanda dos bens, a análise não tratará do segundo estágio proposto por Rosen (1974). As equações de FPH foram estimadas individualmente para cada ano do período 1954-1988, operacionalizando-se as devidas correções para multicolinearidade, heterocedasticidade e dependência serial, quando necessárias.

do selo. Por esse motivo é que há um salto no nível de proporções dessas imagens em relação às demais, que passou de $55,6 \%$ para $64,5 \%$. 
Os modelos gerais nas formas linear, semilogarítmica e dupla-logarítmica das regressões foram:

a) Linear:

$V R_{i}=\beta_{0}+\beta_{1} D P P F_{i}+\beta_{2} D P P G_{i}+\beta_{3} D P P A C A M_{i}+\beta_{4} D P P A C A Z_{i}+\beta_{5} D P P A M A Z_{i}+$ $+\beta_{6} D T X V G_{i}+\beta_{7} D P R D T_{i}+\beta_{8} D D T_{i}+\beta_{9} N D T_{i}+\beta_{10} D P E R C_{i}+\beta_{11} D P R C O R_{i}+\beta_{12} D I M A L G_{i}+$ $+\beta_{13} D_{I M O U T}+\beta_{14} V F_{i}+\beta_{15} D S N_{i}+\beta_{16} I D_{i}+\beta_{17} D 2 S_{i}+\beta_{18} D 3 S_{i}+\beta_{19} D 4 S_{i}+\beta_{20} D 5 S_{i}+$ $+\beta_{21} D 6 S_{i}+\beta_{22} D E N V_{i}+\beta_{23} D B S S_{i}+\beta_{24} D V R G R_{i}+\beta_{25} D V R C P P_{i}+\beta_{26} D \operatorname{PPTIN}_{i}+\beta_{27} D V R T X_{i}+$ $+\beta_{28} D V R D T_{i}+\beta_{29} D V R I M P_{i}+\beta_{30} D L G M R G_{i}+\beta_{31} D V R C O R_{i}+\varepsilon_{i}$

b) Semilogarítmica: a única diferença, em relação à formulação linear, é que a variável dependente é logaritimizada; utiliza-se $L O G\left(V R_{i}\right)$ ao invés de $V R_{i}$.

c) Dupla-logarítmica: difere da formulação semilogarítmica, porque logaritmizamse as variáveis explicativas não dummies, ou seja, utilizam-se $\operatorname{LOG}\left(N D T_{i}\right)$, $L O G\left(V F_{i}\right)$ e $L O G\left(I D_{i}\right)$ como variáveis explicativas.

As estimações foram feitas para cada um dos 35 anos da base de dados (1954 a 1988) que, em conjunto, geraram 1085 betas estimados. Eles formam o conjunto dos preços implícitos das $K$ características para cada ano, i.e., $\hat{\beta}_{k}^{t}=\hat{p}_{k, t}$ para todo $t=1954, \ldots, 1988$ e $k=1, . ., 31$.

\subsection{Carteiras Eficientes de Markowitz}

De posse dos preços implícitos anuais estimados de cada característica, foram calculados os inputs necessários à análise de carteiras eficientes. Os retornos implícitos, suas volatilidades e correlações foram calculados com base nas seguintes fórmulas: seja $\hat{p}_{k, t}$ o preço implícito do $k$-ésimo atributo na data $t$ e $\left\{\hat{p}_{k}\right\}_{t=1954}^{1988}$, a série temporal de preços do $k$-ésimo atributo. Desta série de preços, construiu-se a série de retornos implícitos para cada atributo $k,\left\{\hat{r}_{k}\right\}_{t=1955}^{1988}$, onde $\hat{r}_{k, t}=\ln \left(\frac{\hat{p}_{k, t}}{\hat{p}_{k, t-1}}\right) * 100$. Com a série $\left\{\hat{r}_{k}\right\}_{t=1955}^{1988}$, para todo $k$, foram calculados os retornos médios e as 
variâncias e covariâncias de cada uma das características, conforme as seguintes fórmulas: (i) o retorno médio do $k$-ésimo atributo é dado por $\overline{\hat{r}}_{k}=\frac{\sum_{t=1}^{T} \hat{r}_{k, t}}{T}$; (ii) a volatilidade dos retornos de cada atributo $k$ foi calculada como a variância não condicional deste retorno, $\sigma_{\hat{r}_{k}}^{2}=\frac{\sum_{t=1}^{T}\left(\hat{r}_{k, t}-\overline{\hat{r}}_{k}\right)^{2}}{T}$, e (iii) as correlações não condicionais dos retornos de cada par de atributos $\left(\begin{array}{lll}k & \text { e } & m\end{array}\right)$ foram obtidas tal como $\rho_{\hat{r}_{k, m}}=\frac{\sum_{t=1}^{T}\left(\hat{r}_{k, t}-\overline{\hat{r}}_{k}\right)\left(\hat{r}_{m, t}-\overline{\hat{r}_{m}}\right)}{\sqrt{\sigma_{\hat{r}_{k}}^{2} \sigma_{\hat{r}_{m}}^{2}}}$.

Com as séries dos retornos implícitos, $\left\{\hat{r}_{k}\right\}_{t=1955}^{1988}$, calculou-se também algumas estatísticas descritivas: médias aritméticas, medianas, máximos e mínimos, desvios padrão, coeficientes de variação, assimetria, curtose, estatística de Jarque-Bera e p-values. O risco é medido pelo desvio padrão e duas medidas foram utilizadas para informar as relações entre ele e o retorno: (a) o coeficiente de variação do $k$-ésimo ativo, $C V_{k}=\frac{\sigma_{k}}{\hat{r}_{k}}$, que mede o grau de risco em relação ao retorno, e (b) a razão de informação (ou medida de performance ajustada ao risco), $R I_{k}=\frac{1}{C V_{k}}$, que mede o retorno em relação ao risco.

De posse dos retornos médios das 31 características filatélicas e das estimativas das volatilidades e correlações históricas, parte-se para a análise de portfólio. A carteira eficiente de Markowitz (1959) é obtida como uma combinação de ativos que maximiza o retorno esperado do portfólio, sujeito à restrição de que a variância do retorno do portfólio não exceda um determinado limite previamente especificado. Este problema de otimização pode ser construído de outra forma: o investidor procura minimizar a variância do retorno do portfólio, sujeito à restrição sobre o patamar do seu retorno esperado. ${ }^{20}$ É apresentada aqui somente uma formulação

20 Conforme Alexander (2005), a alocação de ativos partindo do conceito de variâncias-covariâncias é muito limitada, porque nos modelos de risco-retorno as tendências de longo prazo dos preços dos ativos são eliminadas, embora possam sugerir informações decisórias importantes. Para ela, o conceito de cointegração das séries de preços (movimento conjunto dos preços dos ativos) seria mais adequada para a alocação de ativos no longo prazo. Esta questão foi introduzida aqui porque decisões de investimento em ativos tangíveis requer considerar questões de apreciação, preços, retornos, volatilidades e liquidez, principalmente no longo prazo. Uma vez que a proposta deste estudo é mostrar uma aplicação alternativa aos preços implícitos estimados, não são discutidas as questões teóricas e práticas referentes à cointegração dos preços desses ativos. 
do problema de obtenção de carteiras eficientes via programação quadrática, qual seja: minimizar a soma ponderada das variâncias-covariâncias dos retornos dos 31 ativos nos contextos em que a venda a descoberto não é permitida e em que a taxa livre de risco não existe. ${ }^{21}$ Desse modo, o problema de otimização para obtenção da carteira eficiente é:

$$
\underset{w_{1} \ldots w_{31}}{\operatorname{Min}} \sigma_{1}^{2} w_{1}^{2}+\ldots+\sigma_{31}^{2} w_{31}^{2}+2 \sigma_{1,2} w_{1} w_{2}+\ldots+2 \sigma_{30,31} w_{30} w_{31}
$$

sujeito a $\sum_{k=1}^{3} w_{k}=1, \sum_{k=1}^{31} w_{k} \overline{\hat{r}_{k}}=\overline{R_{P}}$ e $w_{k} \geq 0, \forall k$,

onde: $w_{k}$ é participação porcentual do atributo $k$ na carteira; $\overline{R_{P}}$ é o retorno médio preestabelecido para a carteira a ser formada.

Para a construção efetiva das carteiras eficientes de Markowitz, foi utilizado o software The Investment Portfólio, de Elton, Gruber \& Blake With Intellipro Inc., que gerou a solução $w_{1}^{*}, \ldots, w_{3}^{*}$ para o problema de minimização acima exposto.

\section{Apresentação e Análise dos Resultados}

\subsection{Funções Preço Hedônico Estimadas}

A escolha, dentre as três formas funcionais, daquela cujos betas estimados seriam utilizados no cálculo dos retornos implícitos foi estabelecida a partir do teste de McKinnon-White-Davidson, conforme sugere Gujarati (2000). Com base nos dados referentes ao ano de 1988, foram comparadas a linear com a semilogarítmica e a linear com a dupla logarítmica. Os resultados dos testes levaram à rejeição da hipótese de linearidade da forma funcional, ao nível de significância de 1\%, tanto na primeira quanto na segunda comparação. ${ }^{22}$ Entretanto, escolheram-se as estimativas geradas pela forma semi-logarítmica: (i) seguindo a literatura hedônica em estudos de objetos colecionáveis (BUELENS; GINSBURGH, 1993; HUANG,

21 Elton e Gruber (1995) apresentam detalhadamente os modelos para obtenção das carteiras eficientes nos contextos de: (a) ausência de taxa livre de risco e venda a descoberto não permitida; (b) ausência de taxa livre de risco e venda a descoberto permitida; (c) presença de taxa livre de risco e venda a descoberto não permitida, e (d) presença de taxa livre de risco e venda a descoberto permitida.

22 Gujarati (2000) afirma que somente modelos com a mesma variável dependente e mesmo número de observações podem ser comparados com base no R2 e R2 ajustado. 
2001); (ii) por ser mais fácil a transformação ${ }^{23}$ dos coeficientes estimados em preços implícitos, e (iii) pelo fato de os resultados serem bem aproximados aos do modelo dupla-logarítmico.

Também foi feita a estimação do modelo com a transformação Box-Cox para o ano de 1988. Embora este procedimento tenha o mérito de ser mais flexível que os anteriores, de gerar resíduos homocedásticos e normalmente distribuídos e permitir que a própria base de dados revele a forma funcional mais adequada para o modelo, é incapaz de atestar a significância dos coeficientes estimados, que é uma das metas do pesquisador. Nesse sentido, é preferível adotar uma especificação que permita o teste adequado da significância das variáveis relevantes que determinam o preço do bem composto à flexibilidade (HERMANN; HADDAD, 2003).

Em termos dos sinais, a variável DPPTIN apresentou sinal negativo nos anos 1954, 1959 a 1963, 1966 a 1968 e de 1976 a 1978. A variável DVRIMP só apresentou sinal negativo na regressão referente ao ano 1968, e a variável DBSS, no ano 1976. Esses sinais eram inesperados, pois pressupunha-se que as características "papel tintado", "presença de erro de impressão" e "selo bisseto" eram adicionadoras de valor à cotação média de um selo. As variáveis DPPF e DIMOUT permaneceram com coeficientes negativos em todos os anos estimados. A variável DPRDT apresentou sinal negativo nos anos 1967, 1971, 1974, 1979, 1980, 1982 e de 1984 a 1988. A variável DDT, em 1979 e de 1982 em diante. A variável DPPAMAZ, nos anos 1970 e de 1976 a 1978. E as variáveis DPPG e DPPACAZ apresentaram sinais negativos nos anos 1976 a 1978. Todas as demais variáveis tiveram sinal positivo. Em particular, o sinal positivo da variável ID (quanto mais velha a peça, mais rara, mais valorizada), para todas as regressões, está conforme ao resultado encontrado por Schnitzel (1979).

Todos os anos tiveram regressões globalmente significantes, uma vez que, para cada ano, o teste $\mathrm{F}$ da regressão não foi rejeitado. Em termos individuais, 17 variáveis (DPPF, DPPACAM, ${ }^{24}$ DPPACAZ, DPRCOR, DIMOUT, VF, DSN, ID, D2S, D3S, D4S, D5S, D6S, DENV, DVRDT, DLGMRG e DVRTX) ${ }^{25}$ foram estatisticamente significantes para todos os anos. ${ }^{26}$ As variáveis que na maioria dos anos foram estatisticamente significantes são: DTXVG, DIMALG, DBSS, DPPG, DPPTIN, DVRCOR, DVRGR e DPRDT. A variável DPPACAZ, nos anos de 1970 e 1976 a 1978. DVRIMP, nos anos de 1968, 1979, 1982 a 1984. DPERC, em 1954, 1957,

23 Gujarati (2000, p. 529) sugere a utilização da regra de Halvorsen e Palmquist: tomar o antilog (na base e) dos coeficientes estimados e subtrair um.

24 As únicas exceções a esta variável foram nos anos de 1979 e 1985.

25 Exceto para o ano de 1968.

26 O nível de significância para a maioria das estimativas é de $1 \%$. 
1958, 1971 e 1972. DDT e NDT só foram significantes em 1979 e a partir de 1982. Por último, DVRCPP, nos anos de 1976 a 1979 e em 1982.

A constante só foi estatisticamente significante nas regressões dos anos 1982 e 1985, levando a modelos que desconsideram o intercepto. Cabe lembrar que a retirada da constante faz com que o coeficiente de determinação, $R^{2}$, do modelo deixe de ser uma medida confiável de ajustamento. Além disso, conduziria à possibilidade de a cotação média de uma peça filatélica ser nula se nenhuma das características consideradas estivesse presente na peça. Entretanto, não existe uma única peça filatélica que não possua pelo menos uma das características que geraram preços implícitos estatisticamente diferentes de zero.

Em relação à análise dos resíduos, observou-se que a hipótese de normalidade só não foi rejeitada, pelo teste de Jarque-Bera, para as regressões de 1954, 1957 e 1959 (ao nível de significância de 5\%), 1960 a 1970 e 1973 a 1975. Porém a quantidade de observações permite que as distribuições dos resíduos sejam aproximadas pela normal (e os histogramas gerados corroboram esta afirmativa).

Em termos de heteroscedasticidade dos resíduos, em todos os modelos e para todos os anos, ela esteve presente, conforme os resultados dos testes de White executados. No que diz respeito aos problemas de autocorrelação, embora a literatura de MPH sugira que a regressão hedônica possa conter problemas de correlação estocástica, detectou-se problemas de autocorrelação nas regressões para os anos de 1968, 1975 e 1981. Assim sendo, utilizaram-se os estimadores consistentes para heterocedasticidade e autocorrelação de Newey-West para corrigir esses problemas.

\subsection{Preços Hedônicos Estimados e Retornos Implícitos}

Os resultados das regressões mostraram que os principais determinantes da cotação média de uma peça filatélica do período imperial brasileiro (FPH estimadas), entre 1954 e 1988, foram: papel fino, nas cores acinzentada/amarelada ou acinzentada/ azulada, em textura estriada, impressão em cor, imagem de algarismo ou outra e valor de face (características intrínsecas); ausência de carimbo, idade e quantidade de selos na peça filatélica (características extrínsecas), e presença de variedade na textura do papel, na denteação e na cor impressa. Porém, as variáveis que permaneceram explicativas da cotação média em todos os anos analisados foram: papel fino, papel acinzentado/azulado, presença de cor, presença de outras imagens, valor de face, ausência de carimbo, idade, par de selos, quadra de selos e presença de variedade de denteação. 
Os preços marginais do papel fino permaneceram estáveis durante o período, mas foram responsáveis pela subtração de valor. Assim como a presença de "Outras imagens" na impressão, todas as demais características adicionaram valor à cotação média. Estáveis, e muito baixos, foram os preços marginais anuais da característica "valor de face". Os preços marginais da característica "cor do papel (acinzentada/ azulada)" se mostraram voláteis e com tendência de queda durante o período da análise, conforme apresentado no Gráfico 1 .

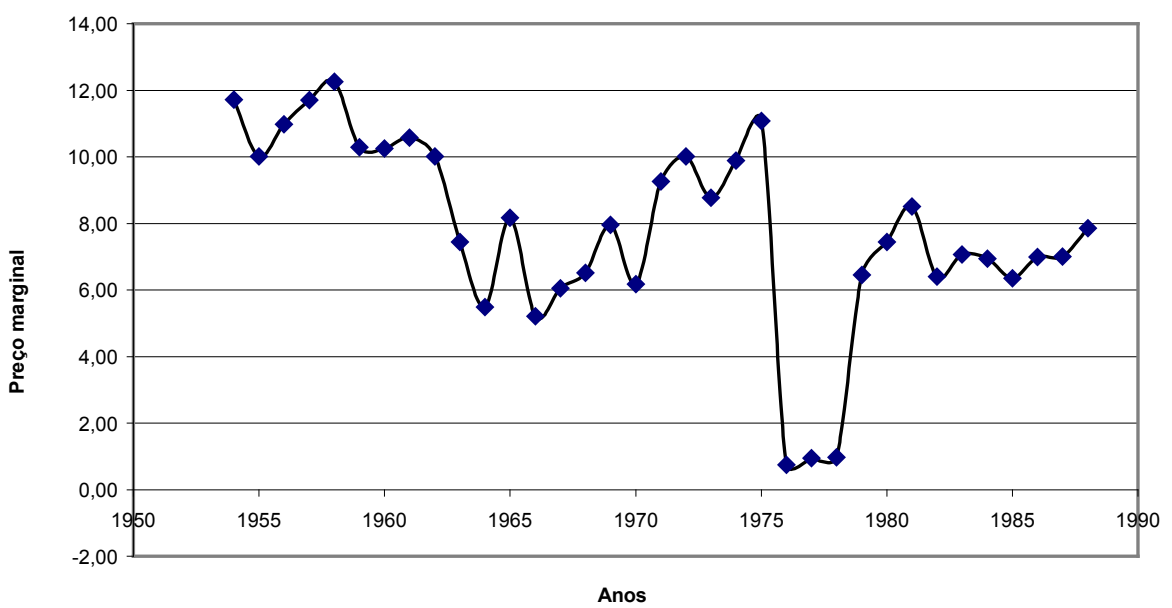

Fonte: Elaboração própria dos autores.

\section{Gráfico 1 - Preço Marginal da Característica "Cor do Papel (Acinzentado/ Amarelado)"}

Este mesmo comportamento foi encontrado para os preços da característica "papel com textura estriada". A característica "presença de cor", embora com preços hedônicos anuais bastante erráticos, apresentou uma ligeira tendência na forma de U: de 1954 a 1979 em queda e, a partir daquele ano, com tendência de alta. Os preços referentes à "presença de imagem de algarismos" mantiveram-se estáveis em torno de 10 reais por longo período (1954 a 1975) e depois saltou para 70 reais e regrediu para 9 reais em 1980.

A característica "idade", além de acrescentar valor, mostrou-se condizente com o senso comum (quanto mais velha a peça, mais rara e mais valiosa), pois apresentou tendência de alta por todo o período de análise, porém com ampliação da variabilidade. Esse comportamento reflete o senso comum de que a raridade tem valor crescente. O Gráfico 2 mostra esse comportamento: 


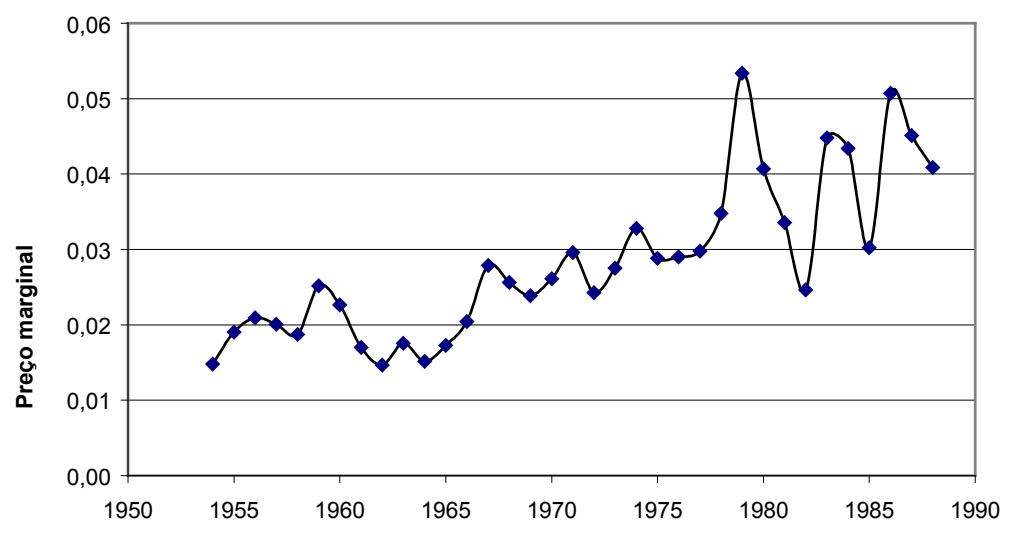

Anos

Fonte: Elaboração própria dos autores.

\section{Gráfico 2 - Preços Marginais da Característica "Idade"}

Comparativamente aos demais preços implícitos, os preços das características "papel grosso", "papel acinzentado/azulado", "imagem de algarismos", "papel com textura estriada", "par de selos", "terno de selos", "quadra de selos", "seis selos", "selos sobre suporte", "selo bisseto", "variedade de textura de papel" e "variedade de tipo de denteação" são os mais elevados. Primeiro, porque dizem respeito a variedades que, como esperado, adicionam maior valor e, segundo, porque refletem o maior grau de escassez relativa das peças filatélicas com tais características.

Algumas características tiveram preços marginais nulos, o que implica dizer que não foram determinantes, naqueles anos, para a cotação média do selo imperial brasileiro. Esta falta de informação força a tomar preços implícitos como nulos nos anos em que os betas não foram estatisticamente significativos. Este procedimento se fez necessário, caso contrário algumas observações importantes para o cálculo dos retornos implícitos seriam perdidas.

Partindo-se das séries temporais dos preços implícitos estimados e devidamente transformados (conforme nota de rodapé 25), calcularam-se os retornos implícitos das características filatélicas. A Tabela 1 sumaria as principais estatísticas descritivas desses retornos. 


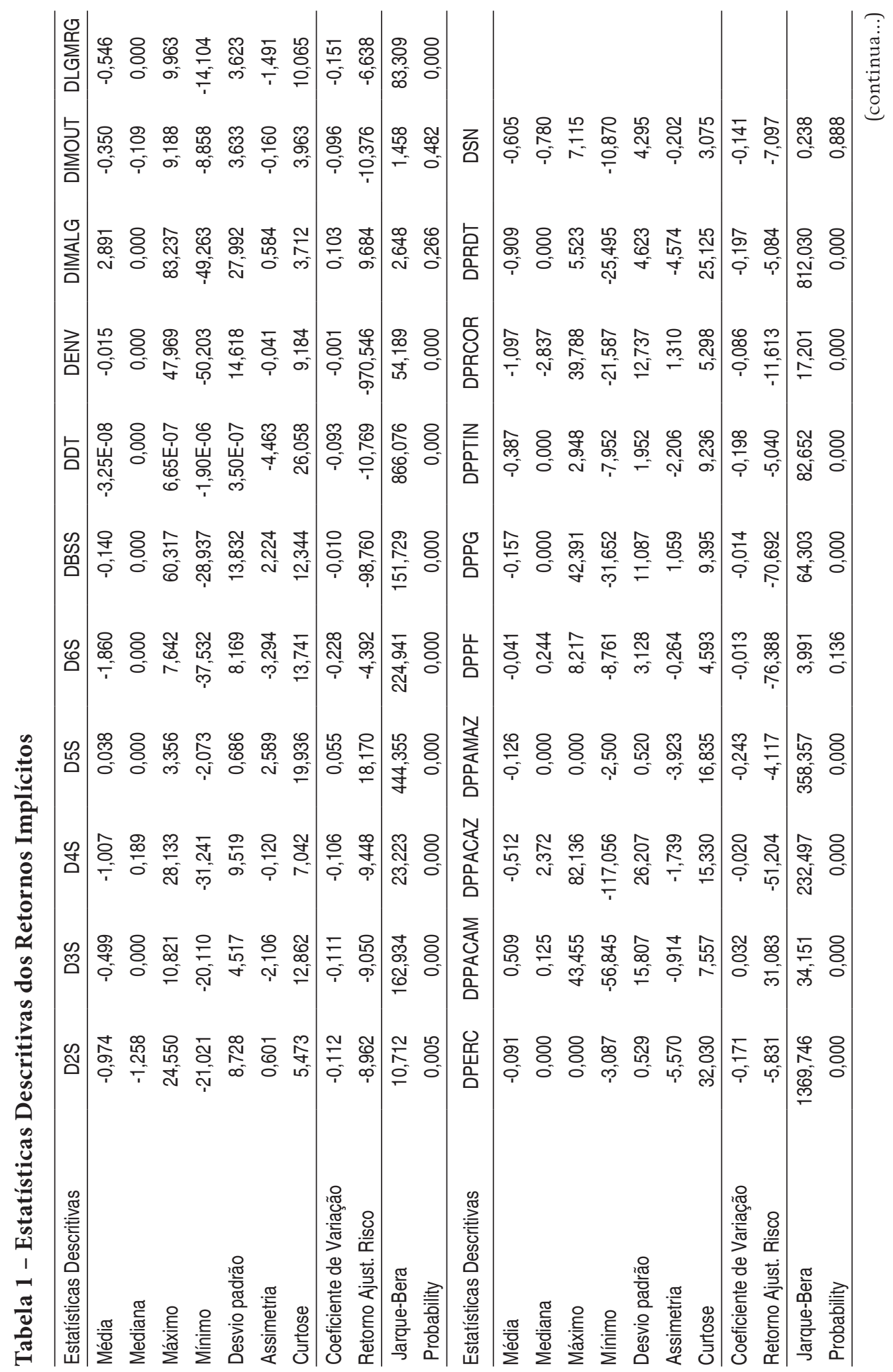




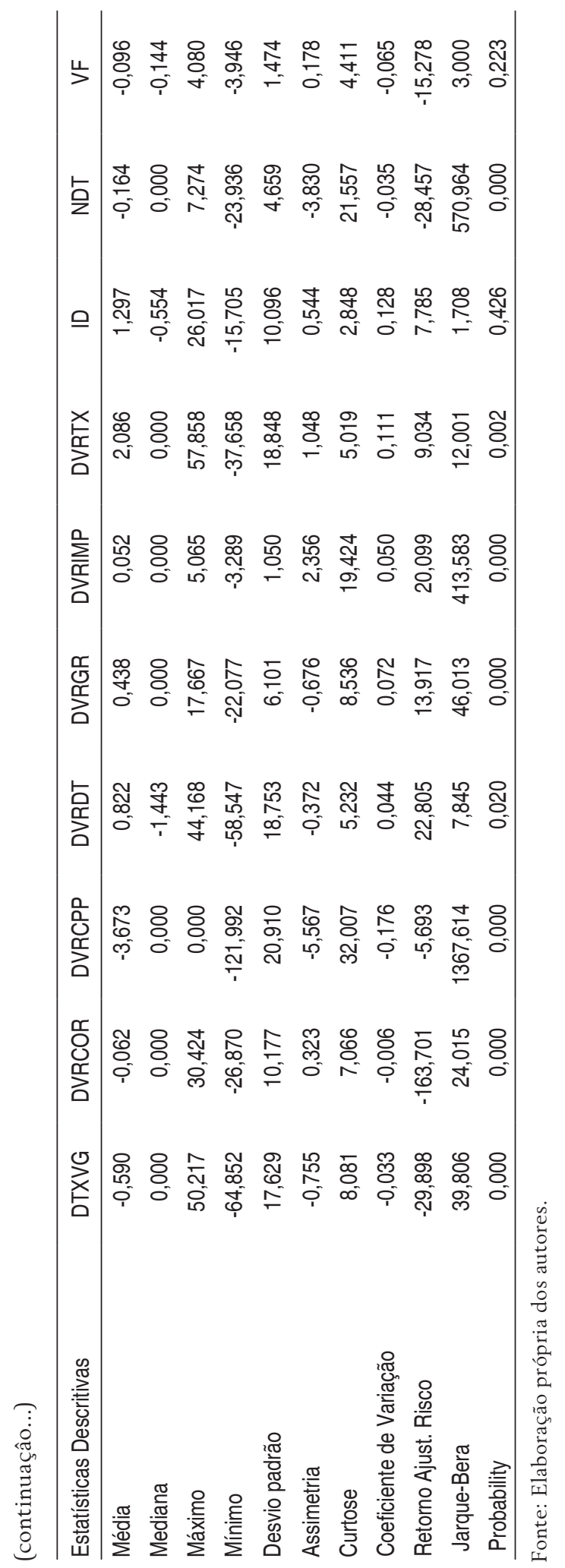


Observa-se que muitos retornos implícitos têm retorno médio negativo, grande dispersão e não são normalmente distribuídos. Somente as características "imagem de algarismos" (DIMALG), "outras imagens" (DIMOUT), "papel fino" (DPPF), "ausência de carimbo" (DSN), "idade" (ID) e "valor de face" (VF) seguiram uma distribuição normal, de acordo com o teste de Jarque-Bera.

Os retornos implícitos seguem a mesma tendência encontrada na literatura empírica de investimentos em objetos colecionáveis. Segundo Frey e Pommerehne (1989) e Burton e Jacobsen (1999), os retornos médios históricos são baixos, com maior volatilidade do que os tradicionais ativos financeiros. Seguem também esta mesma tendência os retornos sobre as peças filatélicas: foram comparados os retornos históricos médios dos selos imperiais brasileiros com os da poupança e do Ibovespa, para o período 1967 a 1988.

\subsection{Carteiras Eficientes de Características Filatélicas}

Dentre os 31 "ativos implícitos" iniciais, foram eliminados da análise, pelo reduzido número de informações nas suas séries temporais (os betas estimados não foram estatisticamente diferentes de zero), seis deles: "papel amarelado/azulado" (DPPACAZ); "presença de denteados" (DDT), "denteação tipo percé" (DPERC), "peça filatélica com cinco selos" (D5S), "variedade na cor do papel" (DVRCPP) e "variedade na impressão" (DVRIMP).

Supondo um cenário totalmente hipotético, com fins de exercício, que não exista taxa livre de risco e que a venda a descoberto não seja permitida, o espaço média-variância com a fronteira eficiente e os ativos implícitos é apresentada na Figura 1. 


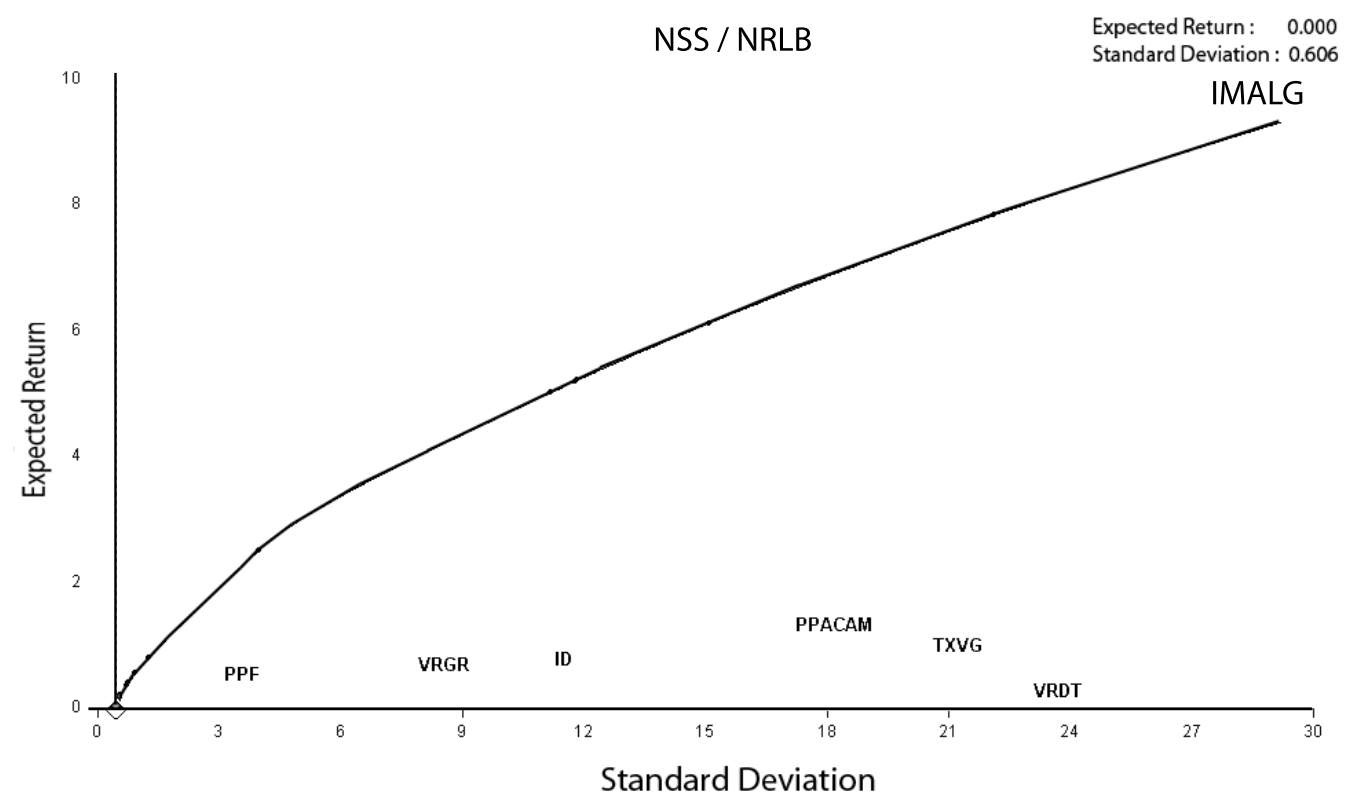

Fonte: Elaboração própria dos autores a partir da análise dos portfólios eficientes extraída do software The Investment Portfólio, versão 2.5.

Figura 1 - Espaço Média-Variância com os Ativos Implícitos e a Fronteira Eficiente

Note-se que o portfólio de variância mínima é aquele que gera taxa nula de retorno e desvio padrão de 0,606\%. Com exceção do ativo implícito "imagem de algarismo" (IMALG), que rendeu próximo a $10 \%$, todos os demais tiveram baixos retornos no período. A carteira de variância mínima seria concentrada em "valor de face", seguida pelas características "papel tintado" e "peça com dois selos", tal como mostrado na Tabela 2.

Convém ressaltar que a carteira contendo características filatélicas é de difícil implementação, uma vez que elas não são vendidas isoladamente. Isto é, a compra de uma característica implica, necessária e simultaneamente, na compra de outras características. Por conta disso, a compra de características adicionadoras de valor (ativos implícitos) poderia estar associada à compra conjunta de passivos implícitos. Não é possível encontrar um selo (que é, ele mesmo, uma "carteira" de atributos), por exemplo, com $18,53 \%$ de uma determinada característica e 6,95\% de outra. Ou ele possui ou não possui aquela característica. Isso, portanto, dificulta a implementação das carteiras de investimento. 
Tabela 2 - Portfólio de Variância Mínima

\begin{tabular}{lc}
\hline Atributos & Pesos \\
\hline DDPF & 4,629 \\
DDPACAM & 0,321 \\
DDPACAZ & 1,695 \\
DTXVG & 0,000 \\
DPRCOR & 0,000 \\
DIMALG & 2,694 \\
VF & 57,925 \\
DSN & 0,000 \\
ID & 1,492 \\
D2S & 8,385 \\
D4S & 0,000 \\
DBSS & 0,493 \\
DVRGR & 0,000 \\
DPPTIN & 17,325 \\
DVRTX & 0,000 \\
DVRDT & 3,630 \\
DLGMRG & 1,432 \\
Retorno Esperado & 0,000 \\
Desvio padrão & 0,606
\end{tabular}

Fonte: Elaboração própria dos autores.

Poder-se-ia, como estratégia de investimento, selecionar peças filatélicas com o maior número possível de ativos implícitos e menor número possível de passivos implícitos. A ampla quantidade de combinações de características com e sem variedades permite a condução desta estratégia e encontrar as peças que mais se ajustariam.

A título de exemplificação, poder-se-ia vislumbrar a peça filatélica que tem os ativos implícitos sugeridos pela abordagem de Markowitz: peça com dois selos em papel fino, tintado com valor de face elevado, com legenda na margem e variedade de denteação. E os selos que melhor se enquadram neste perfil são: Vertical de 300 réis (RHM 17B) ${ }^{27}$ ou Vertical de 600 réis (RHM 18B) ou Coloridos de 280 réis (RHM 21B) ou Cabeça Grande de 100 réis sem denteação (RHM 54SD) ou Cifra de 100 réis sem denteação (RHM 65SD).

Observe-se que, ainda assim, não refletiria carteiras delineadas pela abordagem de Markowitz. Assim sendo, o estágio de construção das carteiras eficientes seria de limitada importância. Ele, no máximo, listaria os ativos implícitos a procu-

27 Número de classificação do catálogo RHM 1988. 
rar e os passivos implícitos a evitar. Mas as carteiras à la Markowitz não seriam alcançadas.

\section{Conclusões e Possíveis Extensões}

Como se sabe, os consultores e corretores costumam recomendar inúmeros tipos de ativos aos seus clientes e, entre eles, alguns ativos tangíveis, tais como: quadros de pintores famosos, vinhos, moedas raras, selos raros, livros raros, objetos de pessoas famosas e outros; que geram fluxos de caixa na data da sua revenda. Assim sendo, é do interesse do investidor tentar acompanhar a trajetória dos preços e dos retornos desses ativos para suas decisões de compra e de revenda.

Nos mercados desses ativos, atuam tanto investidores quanto colecionadores. Portanto, o processo de formação dos preços está condicionado a interesses diversos. Não seria inadequado afirmar que muitas das características que descrevem o objeto de coleção sejam as fontes geradoras de valor de toda a peça. Por isso, o comportamento desses preços marginais também deveria ser acompanhado.

Procurou-se determinar aqui os preços implícitos de uma classe de ativos não convencionais - selos postais do período imperial brasileiro (1843 e 1988). Em particular, estimou-se os preços marginais das características determinantes das cotações médias anuais dessas peças filatélicas, tomando as suas cotações no período 1954-1988. Ademais, uma vez que os investidores observam preços e retornos nas suas tomadas de decisão, propôs-se uma aplicação adicional aos preços implícitos construção de carteiras eficientes de Markowitz.

Escolheram-se, para o estudo empírico, os selos postais imperiais brasileiros por apresentarem variedades raras a partir das características comuns. Além disso, para alguns desses ativos, algumas características são suas principais fontes de agregação de valor.

Empregaram-se duas abordagens teóricas: a primeira - método dos preços hedônicos de Rosen (1974) - para a obtenção dos preços implícitos das características dos selos postais e a segunda - teoria das carteiras eficientes de Markowitz (1952) - para a construção das carteiras eficientes a partir dos retornos implícitos calculados com aqueles preços.

As regressões hedônicas estimadas para cada ano tiveram como forma funcional escolhida a semilogarítmica. Essas regressões geraram resíduos não normais somente para alguns anos (tamanho populacional possibilitou tomá-los como normalmente 
distribuídos), não autocorrelacionados (somente para três anos) e heterocedásticos (ou heteroscedásticos??), cuja causa é supostamente originada na presença de outliers na variável "Valor real da cotação", porém nenhum tratamento foi dado a eles.

Em termos de preços e retornos implícitos, observou-se que nem todas as 31 características tomadas previamente como determinantes das FPH foram estatisticamente significantes para todos os anos. As variáveis sistematicamente relevantes foram: "papel fino", "papel acinzentado/amarelado", "papel acinzentado/azulado", "textura estriada", "presença de cor na impressão", "outras imagens", "ausência de carimbo", "valor de face", "idade, "presença de dois selos na peça filatélica", "presença de quatro selos na peça filatélica", "variedade de textura" e "variedade de denteação". E, dentre estas, somente "papel fino" e "outras imagens" retiram valor da cotação média.

As magnitudes dos preços implícitos foram variadas, mas as características com maiores preços marginais foram: "papel grosso", "papel acinzentado/azulado", "textura estriada", "imagem de algarismos", "presença de quatro selos na peça filatélica", "variedade de textura" e "variedade de denteação". Esse comportamento só não era esperado para a variável "textura estriada". Todos os demais estão relacionados a variedades ou a peças filatélicas de alto valor de mercado. Note-se que, em particular, a característica "ausência de carimbo" teve beta positivo, como esperado.

A análise dos preços e dos retornos implícitos evidenciou um resultado que é condizente com o senso comum dos participantes dos mercados filatélicos: as peças filatélicas mais velhas, principalmente suas variedades (papel acinzentado/amarelado), foram as mais rentáveis dentre todas elas. Além disso, seguindo a tendência encontrada na literatura empírica de investimentos em objetos colecionáveis, os retornos implícitos apresentaram retornos médios históricos baixos e com maior volatilidade, comparados aos tradicionais ativos financeiros. Em particular, esta mesma tendência foi encontrada para o período 1967 a 1988, quando se compararam os retornos históricos médios dos selos imperiais brasileiros com os da poupança e do Ibovespa.

$\mathrm{Na}$ construção dos inputs à análise das carteiras eficientes, verificou-se que somente os ativos implícitos "variedade de gramatura", "papel acinzentado/amarelado", "variedade no tipo de denteação", "idade", "imagem de algarismos" e "variedade de textura" tiveram retornos médios positivos entre 1954 e 1988. Todos os demais foram negativos. 
As carteiras eficientes são difíceis de serem implementadas, pois elas não são vendidas isoladamente e não há maneira de fracionar atributos; uma vez que a peça filatélica tem ou não tem determinada característica. Entretanto, tomando-se a carteira de variância mínima numa situação de inexistência de taxa livre de risco, de não permissão da venda a descoberto, e supondo, simplificadamente, que a carteira à la Markowitz liste somente os atributos que devem constar dela, averiguou-se que ela seria composta de poucos selos: VER300B ou VER600B ou COL280B ou CG100ABRSD ou CF100SD.

Este estudo apresentou algumas limitações. A primeira diz respeito ao problema da compra casada. A ampla quantidade de combinações de características com e sem variedades permite encontrar aquelas financeiramente favoráveis. Para alguns casos, não. Apesar da possibilidade de encontrar peças filatélicas com mais ativos implícitos do que passivos implícitos, a tradução dos pesos das carteiras eficientes em termos de características filatélicas é de difícil implementação. Uma solução possível seria o emprego da programação linear inteira na seleção dos selos que representarão o ativo a ser investido.

Outra limitação diz respeito ao fato de não haver dados referentes às tiragens de selos com variedades; somente dos selos sem variedades. Por isso, estas não foram utilizadas como variáveis explicativas da cotação média do selo postal imperial, conforme feito no estudo de Schnitzel (1979).

Muitas características deixaram de ser avaliadas porque não há informações nos catálogos consultados, tais como: (a) distância entre a margem do selo e a margem da imagem do selo (esta informação seria relevante porque quanto maior o tamanho da margem maior a cotação da peça); (b) posição do carimbo na peça filatélica; (c) nitidez do carimbo; (d) nitidez da impressão.

As cotações para os anos posteriores a 1988 não foram utilizadas neste estudo pelo fato de que os catálogos deixaram de ser publicados anualmente. E aquelas para os anos anteriores a 1954 também não foram utilizadas pela dificuldade de obtê-los.

Para alguns anos, os editores dos catálogos informam que os preços provêm de listas de leilões e de oferta de compra e venda, e, para outros anos, que as cotações derivam de pesquisas com os comerciantes filatélicos. Possivelmente, muitas das cotações utilizadas neste estudo são referentes a "preço de oferta" e não "preço de equilíbrio". Por isso, espera-se que os resultados estejam majorados, visto que os comerciantes teriam interesse em dilatar seus ganhos. 
Cabe lembrar que há potencial para a extensão desta pesquisa. Algumas variáveis poderiam entrar na análise de forma diferenciada, por exemplo, a variável "número de dentes no selo", ao invés de quantitativa, deveria ter sido qualitativa, pois o número de dentes na peça não parece relevante, mas sim o tipo de número de dentes (selos sem denteação, selos com 12 dentes em dois cm, ${ }^{28}$ selos com 13 dentes em dois $\mathrm{cm}$, selos com 13,3 dentes em dois $\mathrm{cm}$ ). Associada à variável "variedade de cor" poderia ser construída uma variável para captar as diferenças de tonalidade da cor em relação à cor "oficial". Entretanto, a definição de tonalidade "mais clara" e "mais escura" requereria um critério que está além do escopo deste estudo.

A análise só se concentrou nos selos do período imperial brasileiro porque é, segundo os especialistas da área, a que contém grande quantidade de variedades e peças raras. Ela poderia ser ampliada e incorporar peças filatélicas dos primeiros anos do período republicano.

Uma vez que a busca da carteira ótima não foi empreendida, sugere-se que novos estudos caminhem nessa direção. Sugere-se também que a técnica aqui desenvolvida seja aplicada nos estudos de investimentos em outros ativos não convencionais, tais como: quadros de pintores famosos, que possuem características passíveis de avaliação (tons, dimensão da obra, tema, principais cores utilizada, idade da peça, estilo do pintor, a quantidade de obras do pintor, o próprio pintor, etc.), assim como atributos dos vinhos, retornos implícitos sobre características de imóveis, etc.

\section{Referências}

ALEXANDER, C. Modelos de mercado: um guia para a análise de informações financeiras. São Paulo: Bolsa de Mercadorias \& Futuros, 2005.

BAJARI, P.; BENKARD, C. L. Demand estimation with heterogeneous consumers and unobserved product characteristics: a hedonic approach. Journal of Political Economy, v. 113, n. 6, p. 1239-76, Dec. 2005.

BARTIK, T. J. the estimation of demand parameters in hedonic price models. Journal of Political Economy, v. 95, n. 1, p. 81-88, Feb. 1987.

BIANCHI, M. Collecting as a paradigm of consumption. Journal of Cultural Economics, v. 21, p. 275-89, 1997.

BROWN, J. N; ROSEN, H.S. On the estimation of structural hedonic price models. Econometrica, v. 50, n. 3, p. 765-768, May 1982.

BUELENS, N.; GINSBURGH, V. Revisiting Baumol's "art as floating crap game". European Economic Review, v. 37, p. 1351-71, 1993.

28 Dois centímetros é a medida padrão que determina o número de dentes num selo. Se em $2 \mathrm{~cm}$ houver 12 furos, então o denteado é 12, se tiver 13,3, então o denteado é 13,3, etc. 
BURTON, B.J.; JACOBSEN, J.P. Measuring returns on investments in collectibles. The Journal of Economic Perspectives, v. 13, n. 4, p. 193-212, Fall 1999.

CARDELL, N S.; KLING, J. L.; PETRY, Glenn. stamp returns and economic factors. Southern Economic Journal, v. 62, n. 2, p. 411-427, Oct. 1995.

DICKIE, M.; DELORME JR, C. D.; HUMPHREYS, J. M. Price determination for a collectible good: the case of rare U.S. coins. Southern Economic Journal, v. 61, n. 1, p. 40-51, July 1994.

ELTON, E., GRUBER, M. Modern portfolio theory and investment analysis. New York: John Wiley \& Sons, 1995.

EPPLE, D. Hedonic prices and implicit markets: estimating demand and supply functions for differentiated products. Journal of Political Economy, v. 95, n. 1, p. 59-80, Feb. 1987.

FABOZZI, F. J. Mercados, análise e estratégia de bônus: títulos de renda fixa. Rio de Janeiro: Qualitymark Ed., 2002.

FREY, B. S.; POMMEREHNE, W. W. Art investment: an empirical inquiry. Southern Economic Journal, v. 56, n. 2, p. 396-409, Oct. 1989.

GUJARATI, Damodar N. Econometria básica. 3. ed. São Paulo: Makron Books, 2000.

HERMANN, B. M.; HADDAD, E. A. Muito além do jardim: mercado imobiliário e amenidades urbanas. São Paulo: Universidade de São Paulo - NEREUS. 2003. (Texto para Discussão n. 04-2003.)

HUANG, S. Asymmetric participation in China's stamp market: hobbyists and investors. Applied Economics, v. 33, n. 8, p. 1039-48, June 2001.

IBBOTSON, R. G.; BRINSON, G. P. Investment markets: gaining the performance advantage. New York: McGraw Hill, 1987.

KAHN, S.; LANG, K. Efficient estimation of structural hedonic systems. International Economic Review, v. 29, n. 1, p. 157-166, 1988.

KANE, A. Coins: anatomy of a fad asset, Journal of Portfolio Management, v. 1, n. 2, p. 44-51, Winter 1984.

LANCASTER, K. A new approach to consumer's theory. Journal of Political Economy, n. 74, p. 132-157, Apr. 1966.

LUCKING-REILEY, D. Auctions on the internet: what's being auctioned, and how? The Journal of Industrial Economics, v. 48, n. 3, p. 227-52, Set. 2000a.

. Vickrey auctions in practice: from nineteenth-century philately to twentyfirst-century e.commerce. The Journal of Economic Perspectives, v. 14, n. 3, p. 183-92, Summer 2000b.

MARKOWITZ, H. Porfolio selection. The Journal of Finance, v. 7, n. 1, p. 77-91, Mar. 1952. 
. Porftolio selection: efficient diversifications of investments., New York: John Wiley \& Sons, 1959. (Cowles Foundation Monograph, n. 16)

ROSEN, S. Hedonic prices and implicit markets: product differentiation in pure competition. Journal of Political Economy, v. 82, p. 34-55, Jan./Feb. 1974.

SÁEZ, A. M.; ACHAERANDIO, Y. S. Measuring the efficiency of the international philatelic auction sector. Portugal, 2004. Disponível em: http://www4.fe.uc. pt/30years/papers/88.pdf. Acesso em: 13 mar. 2007.

SCHNITZEL, P. A note on the philatelic demand for postage stamps. Southern Economic Journal, v. 45, n. 1-4, p. 1261-65, Apr. 1979.

SHEPPARD, S. Hedonic analysis of housing markets. In: CHESHIRE, P.; MILLS, E. S. Handbook of regional and urban economics. Amsterdan: North-Holland, 1999. v. 3, cap. 41, p. 1595-1635.

TAYLOR, W. M. The estimation of quality-adjusted rates of return in stamp auctions. The Journal of Finance, v. 38, n. 4, p. 1095-110, Set. 1983.

. The cointegration of auction price series. Managerial Finance, v. 21, n. 6, p. 35-44, 1995.

VILLANI JR., A. Evidencias empíricas de leilões na internet: selos na eBay. 2001. $101 \mathrm{f}$. Dissertação (Mestrado em Economia) - Faculdade de Economia, Administração e Contabilidade, Universidade de São Paulo, São Paulo, 2001. 